\title{
Three-dimensional quantitative analysis of adhesive remnants and enamel loss resulting from debonding orthodontic molar tubes
}

Joanna Janiszewska-Olszowska ${ }^{*}$, Katarzyna Tandecka², Tomasz Szatkiewicz², Katarzyna Sporniak-Tutak ${ }^{3}$ and Katarzyna Grocholewicz'

\begin{abstract}
Aims: Presenting a new method for direct, quantitative analysis of enamel surface. Measurement of adhesive remnants and enamel loss resulting from debonding molar tubes.

Material and methods: Buccal surfaces of fifteen extracted human molars were directly scanned with an optic blue-light 3D scanner to the nearest $2 \mu \mathrm{m}$. After $20 \mathrm{~s}$ etching molar tubes were bonded and after $24 \mathrm{~h}$ storing in $0.9 \%$ saline - debonded. Then 3D scanning was repeated. Superimposition and comparison were proceeded and shape alterations of the entire objects were analyzed using specialized computer software. Residual adhesive heights as well as enamel loss depths have been obtained for the entire buccal surfaces. Residual adhesive volume and enamel loss volume have been calculated for every tooth.

Results: The maximum height of adhesive remaining on enamel surface was $0.76 \mathrm{~mm}$ and the volume on particular teeth ranged from $0.047 \mathrm{~mm}^{3}$ to $4.16 \mathrm{~mm}^{3}$. The median adhesive remnant volume was $0.988 \mathrm{~mm}^{3}$. Mean depths of enamel loss for particular teeth ranged from $0.0076 \mathrm{~mm}$ to $0.0416 \mathrm{~mm}$. Highest maximum depth of enamel loss was $0.207 \mathrm{~mm}$. Median volume of enamel loss was $0.104 \mathrm{~mm}^{3}$ and maximum volume was $1.484 \mathrm{~mm}^{3}$.

Conclusions: Blue-light 3D scanning is able to provide direct precise scans of the enamel surface, which can be superimposed in order to calculate shape alterations. Debonding molar tubes leaves a certain amount of adhesive remnants on the enamel, however the interface fracture pattern varies for particular teeth and areas of enamel loss are present as well.
\end{abstract}

Keywords: Orthodontic debonding, Enamel damage, Resin remnants

\section{Introduction}

Bonded molar tubes cover a significant proportion of their buccal surface. After active treatment termination they are debonded, usually using ligature-cutting pliers.

The mode of bond failure has been classified by Strattman et al. [1] into four types:

1. fracture interface lying between adhesive and bracket base

\footnotetext{
*Correspondence: jjo@pum.edu.pl

'Department of General Dentistry Pomeranian Medical, University of Szczecin, al. Powstancow Wlkp. 72, 70-111 Szczecin, Poland

Full list of author information is available at the end of the article
}

2. fracture interface lying between adhesive and enamel surface

3. fracture interface lying partly between adhesive and enamel surface and partly within the adhesive

4. fracture interface lying partly between adhesive and enamel surface, partly within the adhesive and partly between adhesive and bracket base

One of the factors determining different modes of adhesive failure during debonding may be enamel morphology varying between tooth groups. Adhesive remnant index (ARI) according to Årtun and Bergland [2] is assessed according to the following criteria 0 - no adhesive left, 1 - less than half of the adhesive left, 2 - more 
than half of the adhesive remained, 3 - all adhesive left. According to Krell et al. [3] adhesive remnant index criteria are as follows: 1 . All adhesive remains on the tooth, 2. More than $90 \%$ adhesive remains on the tooth, 3 . More than $10 \%$, but less than $90 \%$ adhesive remains on the tooth, 4 . Less than $10 \%$ adhesive remains on the tooth, 5 . No adhesive remains on the tooth. Osorio et al. [4] have calculated Adhesive Remnant Index (ARI) as the quotient of area of residual resin on the tooth and the area of bracket base in percentage.

Although used by numerous authors [4-15] ARI is only a surface - assessment measurement and does not measure the volume of resin left on the teeth. Another method of quantitative residual adhesive assessment has been used by David et al. [16], who have calculated resin remnant weight.

The process of debonding results not only in adhesive remnants, but also causes irreversible enamel loss $[1,11,15,17]$. The failure of the interface between adhesive and enamel removes a layer of enamel.

The aim of the study was to quantitatively assess the amount of enamel loss and adhesive remnants following the debonding of molar tubes.

\section{Material and methods}

This study has been decided to be exempt from approval by the bioethical committee of our university (decision reference No: KB-0012/09/01/2013).

Experimental teeth were human third molars extracted for orthodontic reasons from patients aged 16-24 years. All of them have been inspected for soundness of buccal surface and fifteen teeth free of carious lesions, cracks or restorations have been selected. They were stored in distilled water for 24 hours before bonding. After cleaning with a low speed bristle brush and non-fluoride pumice slurry, rinsing for 10 seconds and air-drying with oil-free compressed air, they have been numbered in sequence and for the purpose of 3D scanning embedded in impression silicone (Bisico S1 Soft, Bisico, Germany) in order to prevent unnecessary movement during manipulation.

In order to check if the sample size is appropriate, an on-line power and sample size calculator was used [18]. The threshold value of clinical significance has been set at $0.05 \mathrm{~mm}$ both for adhesive remnants and enamel loss. At the level of significance alfa $=0.05$ and at the power of the test of 0.80 , the sample size yielded 13 and 14 , respectively.

The area to be bonded was determined as centre of the buccal surface, parallel to the crown long axis in order to simulate the clinical conditions. After $20 \mathrm{sec}-$ onds etching with $35 \%$ phosphoric acid (Ultra Etch, Ultradent, USA), 10 seconds rinsing with water spray and drying with oil-free compressed air, molar tubes (ERA, Farfield, USA) were bonded directly using chemical-cure orthodontic adhesive (Unite, $3 \mathrm{M}$, USA). They were firmly pressed onto the enamel in order to minimize excess material. Excess resin on the margins of the molar tubes was carefully removed with a microbrush. After 10 minutes setting, the teeth with molar tubes bonded were stored in $0.9 \%$ saline solution for 24 hours, rinsed with distilled water to prevent saline crystallization and debonded using ligature cutting pliers positioned occlusally and gingivally in order to gently peel the molar tubes from enamel, similarly as in the clinical conditions.

In order to quantitatively analyze resin remnants and enamel loss, buccal surfaces of all teeth were scanned with a 3D optical scanner (Atos III, Triple Scan, GOM, Germany) before etching, and after debonding, using a lens of the field of $170 \times 130 \times 130 \mathrm{~mm}$. Atos scanner uses the technique of triangulation: two cameras observe the course of stripes projected on the object measured and for each pixel of camera sensor point's coordinations are calculated with high precision (Figure 1). The resulting virtual elements were transformed into reference elements. The precision of the scanner $(2 \mu \mathrm{m})$ is maintained by regular calibration procedure thus error study was not performed.

Alteration of the macrogeometric features of enamel surface resulting from orthodontic debonding has been analyzed using GOM Inspect software (GOM, Braunschweig, Germany) allowing to inspect digitalized models measured by the use of Atos Triple Scan with reference models. Scans of pretreatment enamel surfaces were used as reference for comparisons. Every point of the nominal data has been compared with reference data, thus calculating shape alteration of the entire object analyzed (Figure 2). This analysis enabled calculating residual adhesive volume and heights in different locations of the buccal surface. Superimposition and comparison were proceeded using teeth before bonding as reference and teeth with molar tubes removed - as virtual objects. GOM Inspect software allowed to calculate both adhesive remnants and enamel loss.

\section{Results}

Visual macroscopic assessment of adhesive failure on the molars following molar tubes debonding revealed no adhesive remnants on three of the specimens assessed (Ref. No. 1,10 and 15). Complete coverage of the bonding area with adhesive was found on six teeth (Ref. No. 3, 5, 6, 7, 8, 9). Six teeth had some remnants, whereas some adhesive was visible on the molar tubes bases.

The results concerning the amount of adhesive after debonding have been presented in Table 1 . The volume of adhesive remaining on particular teeth ranged from $0.047 \mathrm{~mm}^{3}$ to $4.16 \mathrm{~mm}^{3}$. The median of adhesive remnant volume was $0.988 \mathrm{~mm}^{3}$. The distribution of 


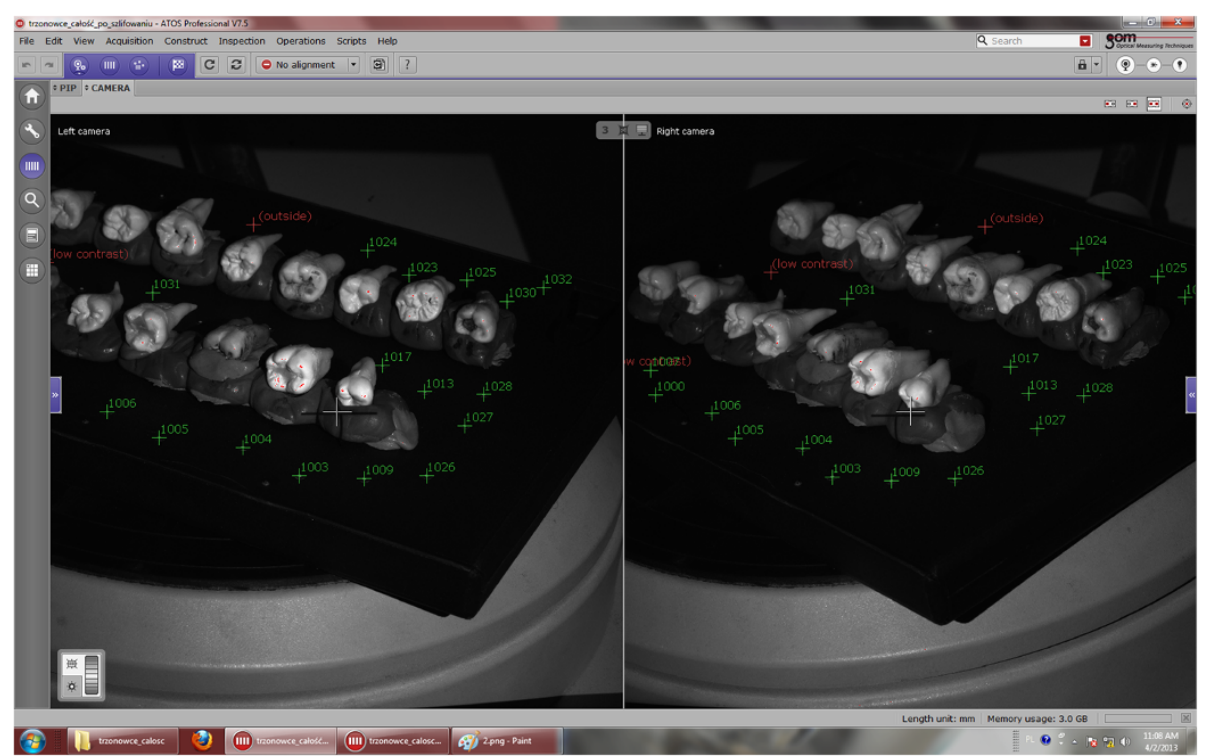

Figure 1 The process of blue-light 3D scanning.

adhesive remnants on particular teeth has been presented in Figure 3.

Enamel loss depth and volume for particular teeth have been presented in Table 2. Maximum depth was $0.207 \mathrm{~mm}$. Mean volume for all the teeth was $0.104 \mathrm{~mm}^{3}$ and maximum volume $1.484 \mathrm{~mm}^{3}$. Extremely low values of adhesive remnant height or enamel loss depth are within the measurement error. The distribution of enamel loss on particular teeth has been presented in Figure 4.

\section{Discussion}

Enamel damage may result from enamel cracking during debonding procedure or grinding residual adhesive after debonding. The area of enamel damage and the volume of enamel loss are dependent on the bracket square surface size [11]. It could be thus less detrimental to use smaller brackets, however bond strength might then be compromised. The molar tubes used in the present study have a wide base and in our opinion, a good fit to the buccal surface, allowing for good bond strength, however the area subjected to treatment alteration covers a substantial proportion of the entire buccal surface.

The 3D blue-light scanning allowed to calculate the height and volume of adhesive remnants avoiding sample sputtering, thus allowing to analyze the enamel surface before etching, and after debonding. Two studies $[19,20]$ quantitatively assessing adhesive remnants and enamel damage on molars has been found, both proceeded using a 3D laser scanning. Direct analysis of enamel surface was impossible due to light reflection [21]. Thus plaster models of the surfaces were made and scanned, causing an inevitable measurement error. This disadvantage was reduced in the present study by using blue light technology, producing a high measurement accuracy of shiny surfaces. Experiment conditions different from an in vivo situation constitute a disadvantage of direct assessing enamel surface mainly due to humidity, which influences bond strength. It has been supported, that in vitro bond strength is higher than that measured in vivo [22].

Debonding with ligature cutting pliers, although simulates the clinical procedure, does not guarantee standarization [12]. This fact was confirmed in the present

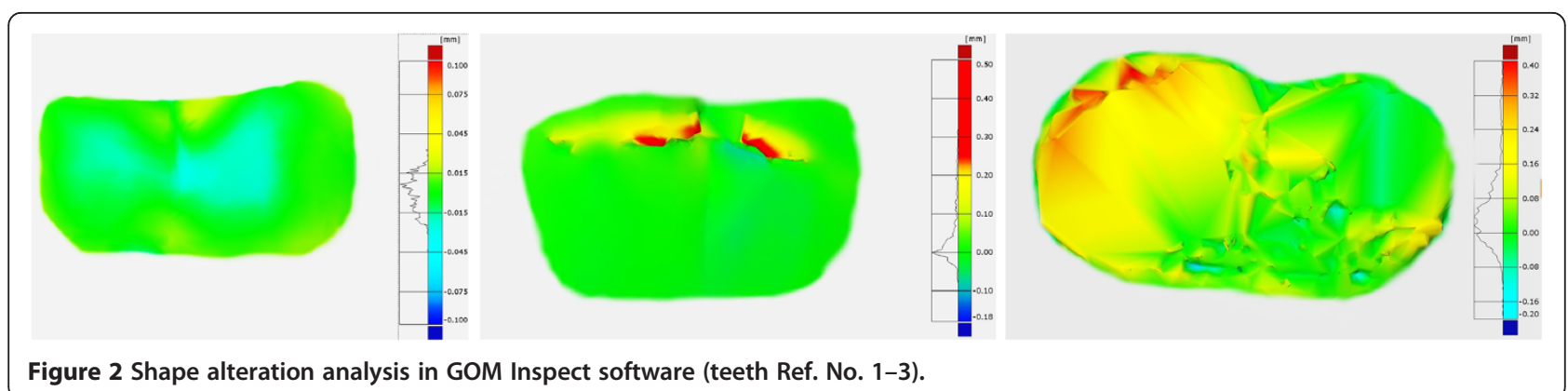


Table 1 Adhesive remnants on particular teeth after debonding

\begin{tabular}{lccccc}
\hline $\begin{array}{l}\text { Tooth } \\
\text { number }\end{array}$ & \multicolumn{5}{c}{ Adhesive remnants } \\
\cline { 2 - 4 } & \cline { 2 - 4 } & \multicolumn{4}{c}{$\begin{array}{c}\text { Volume } \\
{\left[\mathrm{mm}^{3}\right]}\end{array}$} \\
\cline { 2 - 4 } & Mean & SD & Max & Min & 0.047 \\
2 & 0.0099 & 0.0063 & 0.0325 & $1.5 \mathrm{E}-5$ & 0.295 \\
3 & 0.0688 & 0.0779 & 0.4251 & 0.0001 & 1.12 \\
4 & 0.0952 & 0.0776 & 0.4061 & $2.7 \mathrm{E}-5$ & 0.678 \\
5 & 0.1349 & 0.0997 & 0.372 & $3.7 \mathrm{E}-5$ & 3.24 \\
6 & 0.238 & 0.1668 & 0.6986 & 0.0004 & 4.16 \\
7 & 0.1492 & 0.1361 & 0.7606 & $4 \mathrm{E}-6$ & 0.35 \\
8 & 0.0662 & 0.0585 & 0.3323 & 0.0001 & 1.52 \\
9 & 0.084 & 0.0584 & 0.3764 & $2.5 \mathrm{E}-5$ & 1.234 \\
10 & 0.1 & 0.0721 & 0.4727 & 0.0001 & 0.271 \\
11 & 0.0168 & 0.013 & 0.0766 & $5.7 \mathrm{E}-5$ & 1.256 \\
12 & 0.0861 & 0.0646 & 0.2958 & $4.2 \mathrm{E}-5$ & 0.988 \\
13 & 0.0815 & 0.0649 & 0.3609 & $5.8 \mathrm{E}-5$ & 0.148 \\
14 & 0.065 & 0.0698 & 0.3296 & $9.5 \mathrm{E}-5$ & 1.224 \\
15 & 0.1518 & 0.1305 & 0.5752 & 0.0002 & 0.108 \\
\hline
\end{tabular}

study, a diversity of debonding patterns was seen between individual teeth.

In the present study mean height of composite remnants on particular teeth ranged from $0.0087 \mathrm{~mm}$ to $0.238 \mathrm{~mm}$; mean value: $0.084 \mathrm{~mm}$, which is less than mean $200.2 \mu \mathrm{m}$ reported by Ryf et al. [20]. In the present study mean volume of residual composite was $1.1 \mathrm{~mm}^{3}$. A higher value $\left(2.48 \mathrm{~mm}^{3}\right)$ has been reported by Ryf et al. [20].

In the present study a mean enamel loss for particular teeth ranged from $0.0076 \mathrm{~mm}$ to $0.0416 \mathrm{~mm}$, which is less than the mean depth of $44.9 \mu \mathrm{m}$ reported by Ryf et al. [20]. The deepest enamel loss of $297.8 \mu \mathrm{m}$ [20] is higher than $0.2071 \mathrm{~mm}$ from the present study. Median enamel loss volume in the present study was $0.104 \mathrm{~mm}^{3}$, which is more than $0.02 \mathrm{~mm}^{3}$ reported by Ryf et al. [20]. The factors causing discordance between the results could be different materials used (brackets and adhesive), different experiment conditions and different methods of measurements or calculation.

Acid etching and bracket bonding result in resin infiltration into the enamel [23]. It could be supposed that in order to completely remove adhesive remnants, a superficial enamel layer should be removed.

In the present study - debonding with adhesiveenamel bond failure results in adhesive microremnants on the enamel. This is supporting earlier findings [24-26] that macroscopically clean enamel surface is covered by a thin layer of adhesive and underlying the necessity of complete adhesive removal to avoid plaque accumulation and discoloration. Unfortunately, surface scanning does not allow to assess the depth or volume of resin remnants within the enamel (resulting from etching and infiltration).

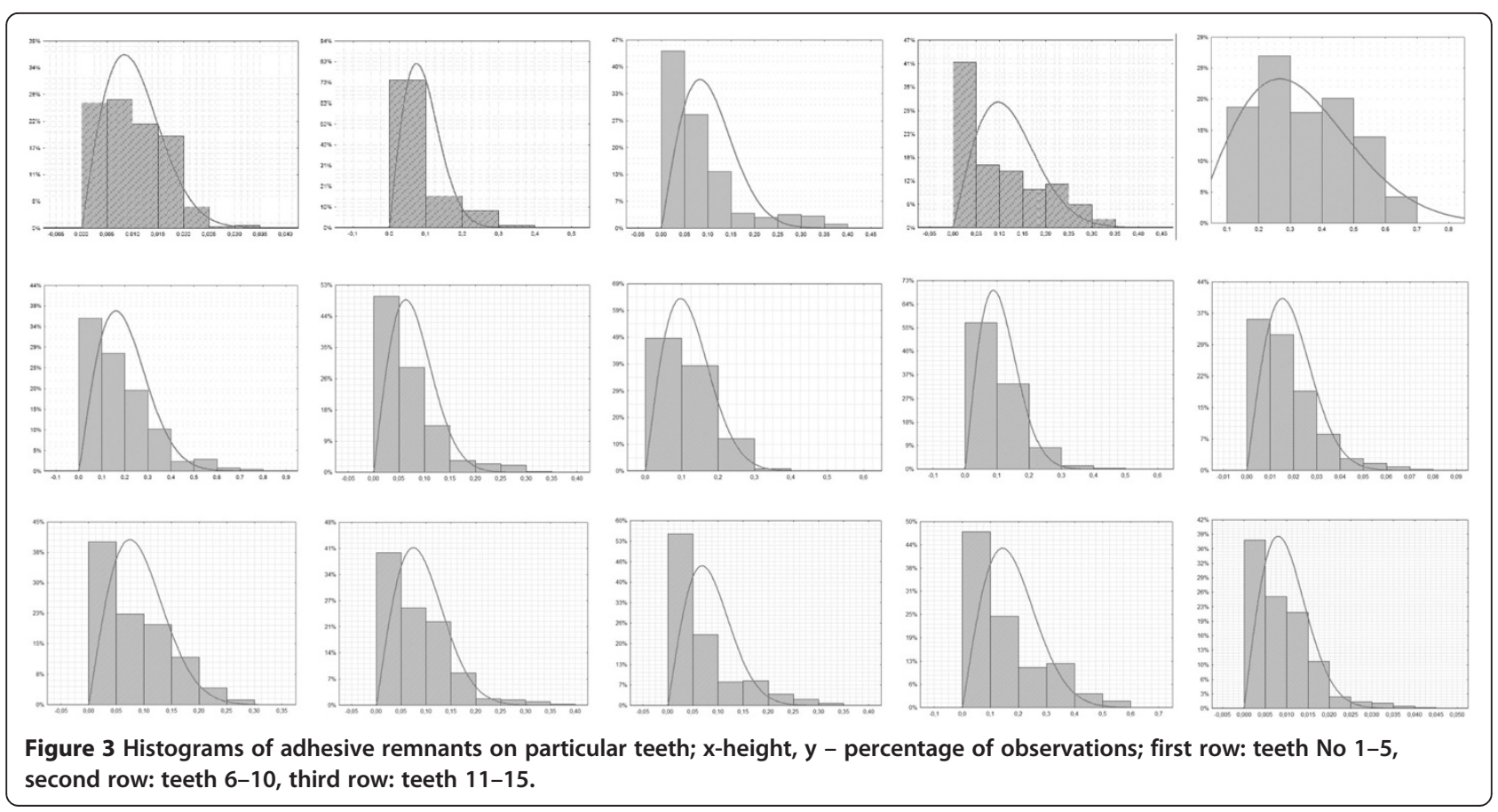


Table 2 Enamel loss on particular teeth after debonding

\begin{tabular}{|c|c|c|c|c|c|}
\hline \multirow{3}{*}{$\begin{array}{l}\text { Tooth } \\
\text { number }\end{array}$} & \multicolumn{5}{|c|}{ Enamel loss } \\
\hline & \multicolumn{4}{|c|}{ Depth [mm] } & \multirow{2}{*}{$\begin{array}{l}\text { Volume } \\
{\left[\mathrm{mm}^{3}\right]}\end{array}$} \\
\hline & Mean & SD & Max & Min & \\
\hline 1 & 0.0113 & 0.0074 & 0.0435 & 0.0001 & 0.076 \\
\hline 2 & 0.0163 & 0.0148 & 0.073 & $1.4 \mathrm{E}-5$ & 0.327 \\
\hline 3 & 0.0326 & 0.0219 & 0.1394 & $2.4 \mathrm{E}-5$ & 0.104 \\
\hline 4 & 0.0142 & 0.0127 & 0.0975 & $4 \mathrm{E}-6$ & 0.419 \\
\hline 5 & 0.0387 & 0.0298 & 0.155 & $5.4 \mathrm{E}-5$ & 0.033 \\
\hline 6 & 0.0134 & 0.0123 & 0.0654 & $6.7 \mathrm{E}-5$ & 0.002 \\
\hline 7 & 0.0416 & 0.03 & 0.2071 & 0.0002 & 0.45 \\
\hline 8 & 0.0263 & 0.0226 & 0.1266 & 3.7E-5 & 0.065 \\
\hline 9 & 0.0213 & 0.0138 & 0.1027 & 0.0002 & 0.037 \\
\hline 10 & 0.0305 & 0.0302 & 0.1677 & $1 \mathrm{E}-6$ & 1.484 \\
\hline 11 & 0.0149 & 0.0125 & 0.0662 & $2.4 \mathrm{E}-5$ & 0.161 \\
\hline 12 & 0.0282 & 0.0203 & 0.0857 & $8 \mathrm{E}-8$ & 0.238 \\
\hline 13 & 0.0246 & 0.0165 & 0.0843 & 0.0002 & 0.087 \\
\hline 14 & 0.0223 & 0.0153 & 0.1083 & $4.4 \mathrm{E}-5$ & 0.098 \\
\hline 15 & 0.0076 & 0.0069 & 0.0375 & $1.4 \mathrm{E}-5$ & 0.15 \\
\hline
\end{tabular}

Al Shamsi et al. [19] have reported a mean remnant adhesive thickness of $31.2 \mu \mathrm{m}$ with light cure adhesive and $102.7 \mu \mathrm{m}$ with adhesive precoated brackets. Enamel loss directly after debonding was not reported. However, according to Alessandri Bonetti et al., [8] bracket precoating had no effect on adhesive remnant index after debonding. However, Kinch et al. [7] found that ARI is dependent on bracket type.
In theory, the bond failure may occur between the bracket base and composite, between the composite and enamel or within the composite (cohesive bond failure). The brackets are removed using pliers exerting a combination of shear, tensile and torque forces [11]. Bond failure between the adhesive and enamel may result in a certain amount of enamel substance loss [16]. Pont et al. [11] using energy dispersive $\mathrm{x}$-ray spectrometry mean area scanning analysis have supported elemental loss of calcium from enamel.

However, in most cases some adhesive is present on the tooth after bracket debonding, which is mechanically removed. The accuracy of the Atos scanner declared by the manufacturer and maintained by regular calibration is $2 \mu \mathrm{m}$. A similar level of precision has been reported by van Vaes et al. [27]. However, no resin remnants or enamel loss directly after debonding were calculated. Adhesive height and volume has an influence on the wear of the tool used for its removal, whereas surface area influences the volume of potential enamel loss.

The results of the present study indicate that the bond failure occurring visually at the interface between bonding material and enamel results in a certain amount of enamel loss. The debonding pattern is thus a cohesive failure of the adhesive within the enamel, therefore both enamel loss and resin remnants may be seen on the same surface fragment. In order to completely remove remnant resin, clean-up procedure should be performed even on macroscopically adhesive-free surfaces. An alternative could constitute leaving some composite remnants, but highly polished.

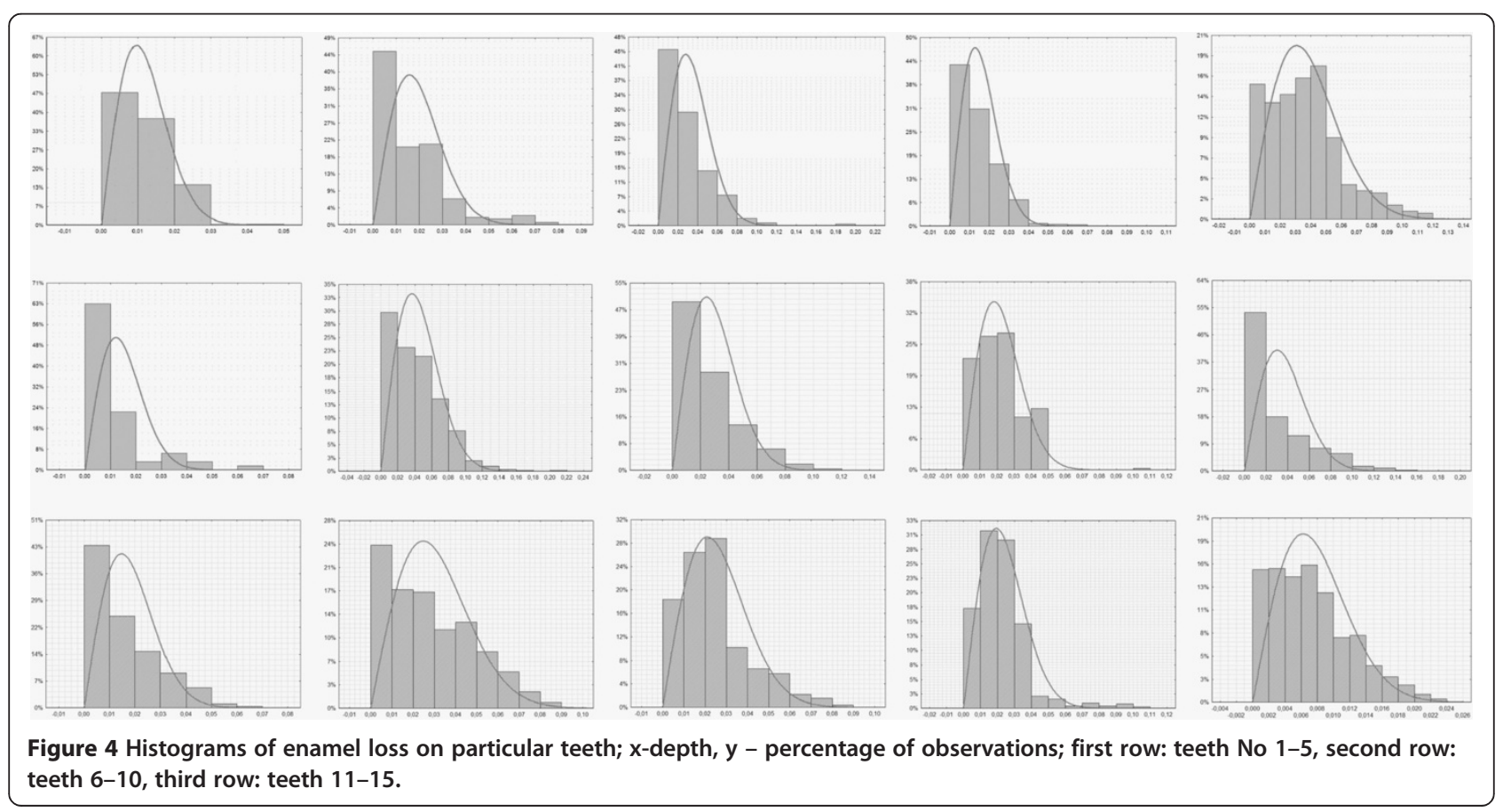




\section{Conclusions}

1. Blue-light 3D scanning is able to provide direct precise scans of the enamel surface, which can be superimposed in order to calculate shape alterations. This method can be recommended for future research.

2. Debonding molar tubes leaves a certain amount of adhesive remnants on the enamel, however the interface fracture pattern varies for particular teeth and areas of enamel loss are present as well.

\section{Competing interests}

The authors declare that they have no competing interests.

\section{Authors' contributions}

JJO study conception and design, data interpretation, writing manuscript. KT 3D scanning and data processing, drawing figures, participation in data interpretation. TS 3D scanning, participation in data interpretation. KST providing material for the study (extracted teeth), participation in manuscript preparation. KG critical revising for intellectual content. All authors have read and approved the final version of the manuscript.

\section{Authors' information}

$J J O$ is a practising orthodontist and assistant professor Department of General Dentistry. KT and TS are engineer scientists and assistant professors Department of Fine Mechanics. KST is a practising specialist in both oral and maxillofacial surgery, associate professor Department of Dental Surgery. KG is a practising specialist in prosthetic dentistry, head of an interdisciplinary Department of General Dentistry.

\section{Acknowledgements}

The study has been founded by Pomeranian Medical University (grant FSN-275-03/13).

\section{Author details}

'Department of General Dentistry Pomeranian Medical, University of Szczecin, al. Powstancow Wlkp. 72, 70-111 Szczecin, Poland. ${ }^{2}$ Department of Fine Mechanics Koszalin, University of Technology, ul. Raclawicka 15-17, 75-620 Koszalin, Poland. ${ }^{3}$ Department of Dental Surgery Pomeranian Medical, University of Szczecin, al. Powstancow Wlkp. 72, 70-111 Szczecin, Poland.

Received: 12 May 2014 Accepted: 2 September 2014

Published: 10 September 2014

\section{References}

1. Stratmann U, Schaarschmidt K, Wegener H, Ehmer U: The extent of enamel surface fractures. A quantitative comparison of thermally debonded ceramic and mechanically debonded metal brackets by energy dispersive micro- and image-analysis. Eur J Orthod 1996, 18:655-662.

2. Artun J, Bergland S: Clinical trials with crystal growth conditioning as an alternative to acid-etch enamel pretreatment. Am J Orthod 1984, 85:333-340

3. Krell KV, Courey JM, Bishara SE: Orthodontic bracket removal using conventional and ultrasonic debonding techniques, enamel loss, and time requirements. Am J Orthod Dentofac Orthop 1993, 103:258-266.

4. Osorio R, Toledano M, García-Godoy F: Enamel surface morphology after bracket debonding. ASDC J Dent Child 1998, 65:313-317-354.

5. Osorio R, Toledano M, Garcia-Godoy F: Bracket bonding with 15- or 60-second etching and adhesive remaining on enamel after debonding. Angle Orthod 1999, 69:45-48.

6. Miksic M, Slaj M, Mestrovic C: Stereomicroscope analysis of enamel surface after orthodontic bracket debonding. Coll Antropol 2003, 27(Suppl 2):83-89.

7. Kinch AP, Taylor H, Warltier R, Oliver RG, Newcombe RG: A clinical study of amount of adhesive remaining on enamel after debonding, comparing etch times of 15 and 60 seconds. Am J Orthod Dentofacial Orthop 1989, 95:415-421.
8. Alessandri Bonetti G, Zanarini M, Incerti Parenti S, Lattuca M, Marchionni S, Gatto MR: Evaluation of enamel surfaces after bracket debonding: an in-vivo study with scanning electron microscopy. Am J Orthod Dentofac Orthop 2011, 140:696-702

9. Tecco S, Tetè S, D'Attilio M, Festa F: Enamel surface after debracketing of orthodontic brackets bonded with flowable orthodontic composite. A comparison with a traditional orthodontic composite resin. Minerva Stomatol 2008, 57:81-94.

10. Sessa T, Civović J, Pajević T, Juloski J, Beloica M, Pavlović V, Glisić B: Scanning electron microscopic examination of Enamel surface after fixed orthodontic treatment: in-vivo study. Srp Arh Celok Lek 2012, 140:22-28.

11. Pont HB, Ozcan M, Bagis $B$, Ren $Y$ : Loss of surface enamel after bracket debonding: an in-vivo and ex-vivo evaluation. Am J Orthod Dentofac Orthop 2010, 138:387. e1-9; disc. 387-389.

12. Knosel M, Mattysek S, Jung K, Sadat-Khonsari R, Kubein-Meesenburg D, Bauss O, Ziebolz D: Impulse debracketing compared to conventional debonding. Angle Orthod 2010, 80:1036-1044.

13. Chang WG, Lim BS, Yoon TH, Lee YK, Kim CW: Effects of salicylic-lactic acid conditioner on the shear bond strength of brackets and enamel surfaces. J Oral Rehabil 2005, 32:287-295.

14. Ritter DE, Ritter AV, Bruggeman G, Locks A, Tulloch JF: Bond strengths and adhesive remnant index of self-etching adhesives used to bond brackets to instrumented and uninstrumented enamel. Am J Dent 2006, 19:47-50.

15. Brosh T, Kaufman A, Balabanovsky A, Vardimon AD: In vivo strength and enamel damage in two orthodontic debonding methods. J Biomech 2005, 38:1107-1113.

16. David VA, Stanley RN, Bigelow HF, Jakobsen JR: Remnant amount and cleanup for 3 adhesives after debracketing. Am J Orthod Dentofacial Orthop 2002, 121:291-296.

17. Ruppenthal T, Stratmann U, Sergl HG, Czech D: Elementanalytische und quantitative morphometrische Bestimmung von Kunstsoffresten und Schmelzausrissen nach der Abnahme von Metallbrackets. Fortschr Kieferorthop 1992, 53:99-105.

18. Power \& Sample Calculator. http://statisticalsolutions.net/pss_calc.php.

19. Al Shamsi AH, Cunningham JL, Lamey PJ, Lynch E: Three-dimensional measurement of residual adhesive and enamel loss on teeth after debonding of orthodontic brackets: an in-vitro study. Am J Orthod Dentofac Orthop 2007, 131:301.e9-15.

20. Ryf S, Flury S, Palaniappan S, Lussi A, van Meerbeek B, Zimmerli B: Enamel loss and adhesive remnants following bracket removal and various clean-up procedures in vitro. Eur J Orthod 2012, 34:25-32.

21. Fitzpatrick DA, Way D: The effects of wear, acid etching and bond removal on human enamel. Am J Orthod 1977, 72:671-681.

22. Hajrassie MK, Khier SE: In-vivo and in-vitro comparison of bond strengths of orthodontic brackets bonded to enamel and debonded at various times. Am J Orthod Dentofac Orthop 2007, 131:384-390.

23. Fjeld M, Øgard B: Scanning electron microscopic evaluation of enamel surfaces exposed to 3 orthodontic bonding systems. Am J Orthod Dentofacial Orthop 2006, 130:575-581.

24. Caspersen I: Residual acrylic adhesive after removal of plastic orthodontic brackets: A scanning electron microscopic study. Am J Orthod 1977, 71:637-650.

25. Burapavong V, Marshall GW, Apfel DA, Perry HT: Enamel surface characteristics on removal of bonded orthodontic brackets. Am J Orthod 1978, 74:176-187.

26. Gwinnett AJ, Gorelick L: Microscopic evaluation of enamel after debonding: clinical application. Am J Orthod 1977, 71:651-665.

27. Van Vaes H, Matter T, Krejci I: Three-dimensional measurement of enamel loss caused by bonding and debonding of orthodontic brackets. Am J Orthod Dentofac Orthop 1997, 112:666-669.

\section{doi:10.1186/1746-160X-10-37}

Cite this article as: Janiszewska-Olszowska et al.: Three-dimensional quantitative analysis of adhesive remnants and enamel loss resulting from debonding orthodontic molar tubes. Head \& Face Medicine 2014 10:37. 